\title{
Determinants of changes in the regional urban heat island in metropolitan Phoenix (Arizona, USA) between 1990 and 2004
}

\author{
Anthony Brazel ${ }^{1, *}$, Patricia Gober ${ }^{1,2}$, Seung-Jae Lee ${ }^{2}$, Susanne Grossman-Clarke ${ }^{3}$, \\ Joseph Zehnder ${ }^{1,3,4}$, Brent Hedquist ${ }^{1}$, Erin Comparri ${ }^{2}$
}

\author{
${ }^{1}$ School of Geographical Sciences, Arizona State University, Tempe, Arizona 85287-0104, USA \\ ${ }^{2}$ Decision Center for a Desert City, Arizona State University, Tempe, Arizona 85287-8209, USA \\ ${ }^{3}$ Global Institute of Sustainability, Arizona State University, Tempe, Arizona 85287-3211, USA \\ ${ }^{4}$ Department of Mathematics, Arizona State University, Tempe, Arizona 85287-0104, USA
}

\begin{abstract}
We investigated the spatial and temporal variation in June mean minimum temperatures for weather stations in and around metropolitan Phoenix, USA, for the period 1990 to 2004. Temperature was related to synoptic conditions, location in urban development zones (DZs), and the pace of housing construction in a $1 \mathrm{~km}$ buffer around fixed-point temperature stations. June is typically clear and calm, and dominated by a dry, tropical air mass with little change in minimum temperature from day to day. However, a dry, moderate weather type accounted for a large portion of the inter-annual variability in mean monthly minimum temperature. Significant temperature variation was explained by surface effects captured by the type of urban DZ, which ranged from urban core and infill sites, to desert and agricultural fringe locations, to exurban. An overall spatial urban effect, derived from the June monthly mean minimum temperature, is in the order of 2 to $4 \mathrm{~K}$. The cumulative housing build-up around weather sites in the region was significant and resulted in average increases of $1.4 \mathrm{~K}$ per 1000 home completions, with a standard error of $0.4 \mathrm{~K}$. Overall, minimum temperatures were spatially and temporally accounted for by variations in weather type, type of urban DZ (higher in core and infill), and the number of home completions over the period. Results compare favorably with the magnitude of heating by residential development cited by researchers using differing methodologies in other urban areas.
\end{abstract}

KEY WORDS: Urban heat island $\cdot$ Phoenix $\cdot$ Land use change $\cdot$ Urban fringe $\cdot$ Housing development Statistical approach

Resale or republication not permitted without written consent of the publisher

\section{INTRODUCTION}

Metropolitan Phoenix's urban heat island (UHI), the phenomenon of warmer temperatures at the core of the built-up urban area compared with the surrounding rural countryside, has been well documented in the scientific literature (Balling \& Brazel 1987, Brazel et al. 2000, Baker et al. 2002, Hawkins et al. 2004, Fast et al. 2005). Large-scale, rapid urbanization (from fewer than 1 million people in 1970 to almost 4 million today) has typically increased the warm season minimum temperature by $5 \mathrm{~K}$ and the daily temperature by more than $3 \mathrm{~K}$ in a desert environment that is naturally hot and was unfit for large-scale human habitation before the popularization of air conditioning during the 1950s (Cooper 1998, Baker et al. 2002). There is an urgent need among planners and city officials for a more practical understanding of the effects of new construction on the local climate because warmer temperatures reduce human comfort, increase energy and water use, and compromise the region's capacity to market itself as a year-round tourist destination. 
Oke (2006) represented the urban-rural continuum with 7 'urban climate zones' and theorized their effects on climate via variation in roughness, aspect ratio, and percent built area. Following this logic, but adapting the idea to the built environment and settlement history of Phoenix, we divided the area into 5 development zones (DZs): core, infill, agricultural fringe, desert fringe, and exurban (hereafter labeled CORE, INFILL, AGFRINGE, DESFRINGE, and EXURBAN) and then empirically investigated the effects of residential construction and synoptic conditions on June mean minimum temperatures between 1990 and 2004 . Using a data set that combines information from 4 historical weather networks and annual information on new housing construction from the Maricopa Association of Governments (MAG, the local council of governments), we evaluated whether DZ affects temperature, the changes in temperature over the study period, and the way new home construction and synoptic conditions affect temperature. Resulting coefficient estimates will enable local planners to better understand the climatic effects of new home development in different zones of the city.

Our research was undertaken under the auspices of a National Science Foundation Project, the Decision Center for a Desert City (DCDC), that is charged with producing scientific results and decision tools that support better water management decisions in the face of growing climatic uncertainty. Although DCDC's mission is primarily concerned with long-term climate change and annual climate variability, potential interactions between the UHI and regional and global climatic processes and the implications of these processes for water demand and supply also represent important avenues of research. Spatio-temporal analyses of the heat island and its changes over time are vital inputs to other studies of the effects of rising nighttime temperatures on water use, including impacts on lake and pool evaporation.

\section{LITERATURE}

The UHI is the most intensely studied climate feature of cities (Arnfield 2003, Souch \& Grimmond 2006). Generally, researchers use fixed weather stations or mobile transects to study the spatial and temporal air temperature structure of cities. Oke (2006) called for a standardization of methods and communication in urban climatology, and argued that any new placement or use of ongoing fixed stations or mobile surveys in an urban environment for analysis of the UHI should consider (1) the general urban zone within which a site is located, (2) the setting of the immediate site and its surroundings, and (3) the layer of atmosphere being observed, e.g. canopy, roughness sublayer, surface, or outer layer. Grimmond (2006) noted that there are a multitude of data consistency issues-including the exposure of sites, data quality, and station representativeness - in a historical weather network. As a result, there is a continued need to evaluate temperature fields relative to the role of surface/building geometry, land use, vegetation, and patterns of anthropogenic heat release.

Recent research summarized by Souch \& Grimmond (2006) shows that the UHI is primarily a nighttime phenomenon, can occur throughout the year, is dependent on weather conditions (wind, cloud cover, etc.), and generally consists of higher temperatures in the urban core and commercial locations, with lower temperatures in residential and rural sites. Previous research on residential areas and changes in air temperature suggest that single-family housing developments raise nighttime temperatures by 2 to $5 \mathrm{~K}$ above rural background values (e.g. Kuttler et al. 1996, Svensson 2004, Unger 2004, Grossman-Clarke et al. 2005, Alcoforado \& Andrade 2006, Hedquist \& Brazel 2006, Hartz et al. 2006). Our approach was to evaluate spatio-temporal patterns of temperature, by developing relationships among factors that are simultaneously operating at both local (within the city and in rural areas) and regional (climate setting and terrain) scales to gain further insights into the spatial distribution of temperature trends across an urban environment that is both infilling and spreading outward.

The rapidly urbanizing region of central Arizona is an excellent site for evaluating spatio-temporal trends in temperature because of the magnitude of recent growth and urban development, and because of the variety of environments in which this new development occurs (Gammage 1999, Gober 2006). Growth occurs from infilling of the already built-up area and from development at the urban fringe. Moreover, despite the popular image of Phoenix as the epitome of a sprawling metropolis, new residential densities are higher today than in the recent past because of rapid growth, growing land prices, and intense competition for land. According to our calculations based on files of the Maricopa County Assessors' Office, the average lot size of a single-family home constructed in the 1970s was $784 \mathrm{~m}^{2}\left(8434 \mathrm{ft}^{2}\right)$, which reduced to $772 \mathrm{~m}^{2}\left(8308 \mathrm{ft}^{2}\right)$ during the 1980s, $696 \mathrm{~m}^{2}\left(7482 \mathrm{ft}^{2}\right)$ during the 1990s, and $688 \mathrm{~m}^{2}\left(7400 \mathrm{ft}^{2}\right)$ between 2000 and 2003. This means that the built environment does not correspond to traditional expectations of declining densities with distance from the urban core; there is a more even distribution of densities across the Phoenix metropolitan area than Oke's (2006) model would suggest.

Previous empirical and modeling studies of Phoenix's UHI were either short-term in nature, focused on the 
spatial attributes of the heat island (e.g. Brazel et al. 1993, Hawkins et al. 2004, Fast et al. 2005, GrossmanClarke et al. 2005) or limited to a coarse urban-rural dichotomy when specifying temporal dimensions (e.g. Brazel et al. 2000, Baker et al. 2002, Stabler et al. 2005). No study has made use of the annual housing time series database to link air temperature patterns to the process of urbanization as manifested in new housing construction. Our further contribution is in the simultaneous consideration of space and time, and in the choice of urban zones that reflect the urban growth processes of Phoenix in particular, and North American cities more generally.

\section{DATA AND METHODS}

Fixed point, surface weather station network data were used and co-located in a Geographical Information System (GIS) classified by DZ type, together with a spatial housing completion data set. In addition, a synoptic variable was developed for the study period of 1990-2004. The sub-sections below describe the data, variables, and methods used in the statistical analyses.

\subsection{Weather stations}

Weather network data of air temperatures within the urban canopy layer (ca. $2 \mathrm{~m}$ height) were obtained from 4 networks in the metropolitan area: (1) Phoenix Realtime Instrumentation for Surface Meteorological Studies (PRISMS, Pon et al. 1998), (2) Arizona Meteorological Network (AZMET, see http://ag.arizona.edu/azmet), (3) Maricopa County Flood Control District (MCFCD, see http://fcd.maricopa.gov), and (4) over 20 co-op stations obtained from the National Climatic Data Center of the National Oceanic Atmospheric Administration (NCDC, NOAA; data available from www.ncdc.noaa.gov and summarized monthly at www.wrcc.dri.edu). Table 1 summarizes site name, elevation, numbers of homes built within a diameter of $1 \mathrm{~km}$ of a site, and the type of weather network. Fig. 1 shows the distribution of stations and their DZ code. Elevations of the stations ranged from $219 \mathrm{~m}$ to over $976 \mathrm{~m}$. However, most sites clustered near a range of
300 to $450 \mathrm{~m}$. For the array of sites used, no significant correlation was found between minimum temperature and elevation within the station network $\left(r^{2}=0.07\right)$, and thus this was not specifically included in our subsequent multivariate analysis. Data obtained from these networks have been quality controlled (by network specialists or by the state climate office), then systematically organized in a GIS. With the exception

Table 1. Weather stations used in statistical analysis. See Fig. 1 for locations. AGFRINGE: agricultural fringe; DESFRINGE: desert fringe; AZMET: Arizona Meteorological Network; MCFCD: Maricopa County Flood Control District; PRISMS: Phoenix Real-Time Instrumentation for Surface Meteorological Studies; NOAA: National Oceanic Atmospheric Administration

\begin{tabular}{|c|c|c|c|}
\hline $\begin{array}{l}\text { Development zone } \\
\text { (DZ) }\end{array}$ & $\begin{array}{l}\text { Elevation } \\
\text { (m) }\end{array}$ & $\begin{array}{l}\text { Cumulative homes } \\
\text { in } 1 \mathrm{~km} \text { buffer } \\
1990-2004\end{array}$ & Network \\
\hline \multicolumn{4}{|l|}{ EXURBAN } \\
\hline Paloma & 219 & 0 & AZMET \\
\hline Queen Creek & 430 & $26^{\mathrm{a}}$ & AZMET \\
\hline Bartlett Dam & 503 & 0 & NOAA \\
\hline Falcon & 417 & $4^{\mathrm{a}}$ & PRISMS \\
\hline Stewart Mountain Dam & 378 & 0 & PRISMS \\
\hline \multicolumn{4}{|l|}{ AGFRINGE } \\
\hline Litchfield & 309 & 148 & AZMET \\
\hline Waddell & 407 & 39 & AZMET \\
\hline Crossroads & 387 & 968 & MCFCD \\
\hline Chandler heights & 433 & 203 & NOAA \\
\hline Laveen 3S & 342 & 977 & NOAA \\
\hline Litchfield Park & 314 & 320 & NOAA \\
\hline Collier & 309 & 595 & PRISMS \\
\hline Rittenhouse & 426 & 31 & PRISMS \\
\hline \multicolumn{4}{|l|}{ DESFRINGE } \\
\hline Carefree Ranch & 976 & 213 & MCFCD \\
\hline Thunderbird & 436 & 45 & MCFCD \\
\hline Carefree & 772 & 101 & NOAA \\
\hline Fountain & 482 & 316 & PRISMS \\
\hline Pima & 665 & 151 & PRISMS \\
\hline Sun Lakes & 364 & 827 & PRISMS \\
\hline \multicolumn{4}{|l|}{ INFILL } \\
\hline Phoenix Greenway & 401 & 80 & AZMET \\
\hline Scottsdale & 469 & 231 & AZMET \\
\hline $\mathrm{ACDC}$ & 372 & 210 & MCFCD \\
\hline Buckeye & 305 & 130 & NOAA \\
\hline South Phoenix & 354 & 74 & NOAA \\
\hline Youngtown & 345 & 159 & NOAA \\
\hline Corbell & 369 & 569 & PRISMS \\
\hline Sheely & 328 & 152 & PRISMS \\
\hline Stapley & 383 & 74 & PRISMS \\
\hline \multicolumn{4}{|l|}{ CORE } \\
\hline Phoenix Encanto & 335 & $5^{\mathrm{a}}$ & AZMET \\
\hline Durango Complex & 320 & $6^{\mathrm{a}}$ & MCFCD \\
\hline IBW & 377 & $33^{\mathrm{a}}$ & MCFCD \\
\hline Alameda & 360 & $9^{a}$ & PRISMS \\
\hline Arcadia & 380 & $17^{a}$ & PRISMS \\
\hline Pera & 385 & $1^{\mathrm{a}}$ & PRISMS \\
\hline Pringle & 376 & $35^{\mathrm{a}}$ & PRISMS \\
\hline Sky Harbor & 344 & 0 & NOAA \\
\hline Tempe ASU & 357 & $15^{\mathrm{a}}$ & NOAA \\
\hline
\end{tabular}

${ }^{\text {a }}$ Homes completed were not within $200 \mathrm{~m}$ of immediate weather monitor in the buffer zone 


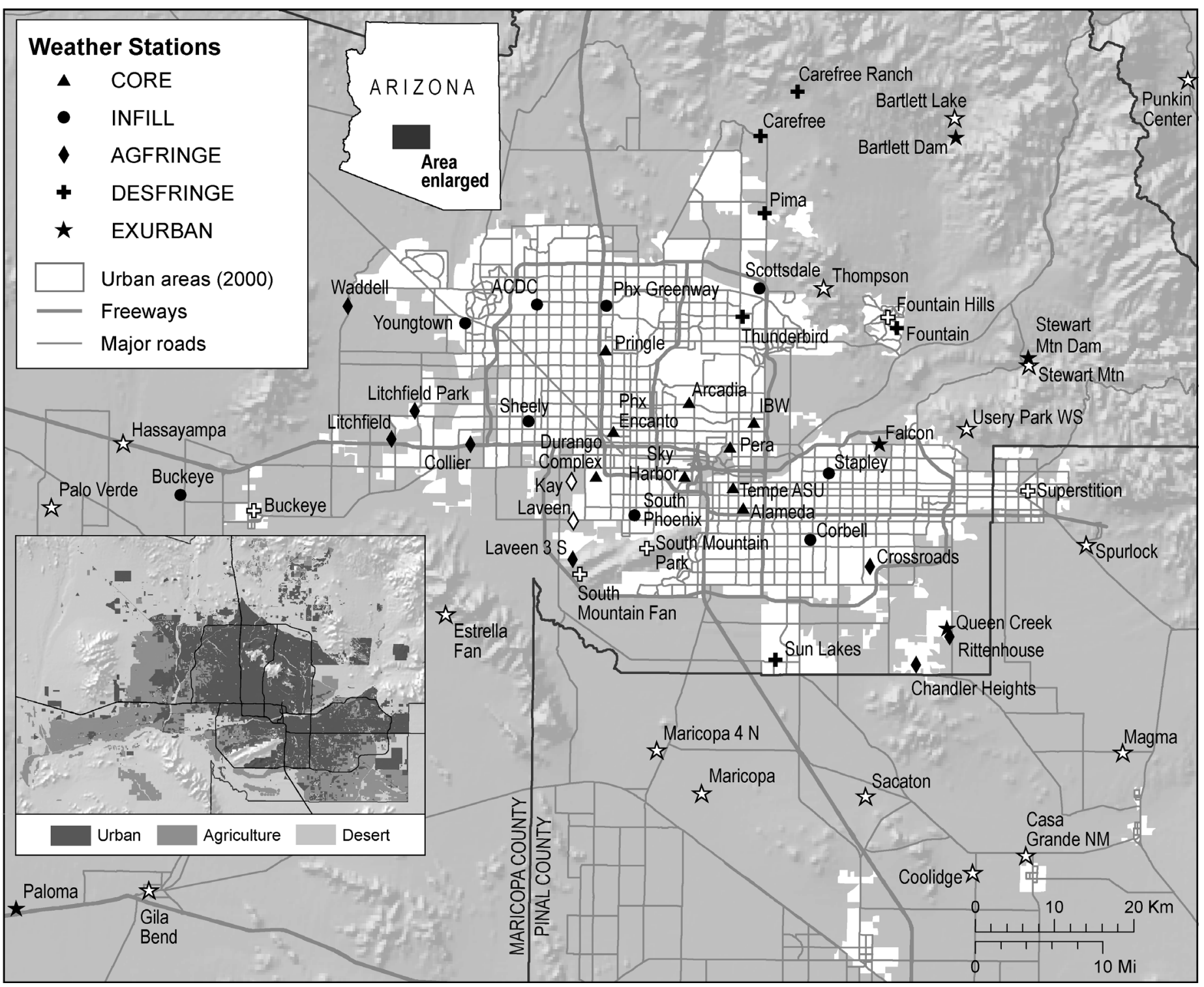

Fig. 1. Weather network stations, coded by development zone (DZ). Filled symbols are those sites used in statistical analysis. Open symbols are sites used additionally for kriging (Fig. 5). Inset shows general distribution of desert, agriculture, and urban lands in Phoenix. See Table 1 for site descriptions. AGFRINGE: agricultural fringe; DESFRINGE: desert fringe

of PRISMS, the network websites (above) contain information on immediate site locales, photos, and other metadata about the sites. Information on PRISMS sites is available through the Office of the State Climatologist at Arizona State University, in cooperation with the Salt River Project (an energy and power company), which manages the monitoring sites (data are displayed at http://data.afws.org/sui/). For this study, we restricted the analysis to a monthly time scale, and to a time of year (June) during which Phoenix experiences relatively hot, clear, calm conditions for most days, an excellent time for UHI evaluation (Brazel et al. 2000). Due to this desert area having over 200 clear days per year and low winds, the UHI phenomenon is evident on a year-round basis and June characteristically represents the nature of the spatial dimension of the UHI.

We encountered missing data for approximately $13 \%$ of the data points, and used spatio-temporal geostatistical tools to estimate the value of these observations by integrating general knowledge based on background information and summary statistics, and site-specific knowledge obtained through experience with the specific situation (Christakos 2000, Christakos et al. 2001). The majority of missing records occurred near the beginning of the time period, because not all sites extended back in time to June 1990. A Bayesian 
maximum entropy (BME) method was employed to estimate missing data and involved 3 steps: (1) a structural stage leading to a prior probability density function (PDF) that uses the mean and covariance functions to model space/time dependencies, trends, and the basic physical structure of the variable (June minimum temperature), (2) a specification stage in which BME assesses data uncertainty in a specific set of sampling points, and (3) an integration stage in which the prior PDF is enriched by blending the 2 knowledge bases through Bayesian conditionalization. The latter stage produces a posterior PDF at all points of interest. We modeled spatio-temporal variability in terms of a covariance model with 2 exponential elements. The first accounts for the short range of spatio-temporal autocorrelation (i.e. 3 decimal degrees in space and 6.5 mo in time), which covers metropolitan Phoenix and entails a seasonal time scale. The second accounts for the long-range correlation (i.e. 46 decimal degrees in space and 60 mo in time). The posterior PDF based on space and time significantly increases the accuracy of our predictions over a purely spatial analytic procedure. There may still be some uncertainty relative to the station network comparability itself, but we consider that less than one-third of the stations (mostly the NOAA network sites in Table 1) that we used would have any problems in this regard.

\subsection{MAG housing completion data}

We used an archived data set available from the MAG, which was based on single-family housing completions in metropolitan Phoenix for each year during the period 1990 to 2004. A completion is recorded when the certificate of occupancy is awarded by its respective municipality. Municipalities in turn submit the georeferenced information to MAG, and MAG assembles the data region-wide and updates the records quarterly. We recognize that the use of this readily available data set acts as a surrogate for the full landscape development process from place to place (homes, streets, yards, etc.). The main advantage is a consistent, complete annual data set for the entire 15 yr study period.

Maps of housing completions for three $5 \mathrm{yr}$ periods illustrate the areas of new housing completions during the study period, the continuous outward movement of the urban fringe of new development, and the relatively large geographic area in which new housing construction is occurring (Fig. 2). The urban fringe in Phoenix is not, as commonly conceived, a narrow band of disturbed landscape, but rather a large area that is gradually but continuously filled in (Gober \& Burns 2002).
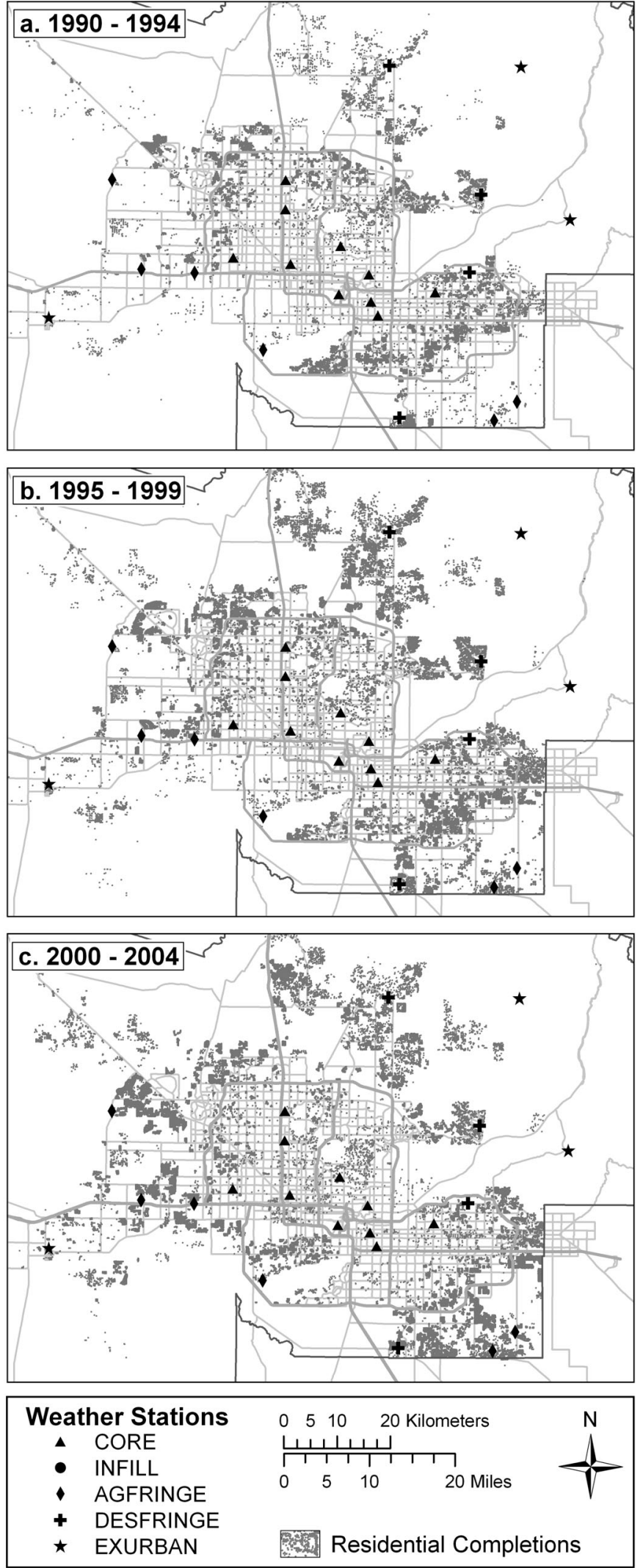

Fig. 2. Residential completions from 1990 to 2004 in 5 yr increments. Gray areas are new housing completions 
Also, using the housing data, we buffered each weather station with a $1 \mathrm{~km}$ diameter buffer, and extracted cumulative numbers of homes completed within this buffer for each year from 1990 to 2004. We performed this analysis in view of Oke (2006), who suggested that influences closer to a site play a major role in driving the variability observed at sites in urban areas (Table 1). We acknowledge that our choice of a $1 \mathrm{~km}$ buffer relaxes an idealistic, more stringent rule for urban site representativeness; however, it does match the modelling resolution of the PSU/NCAR mesoscale model (known as MM5) (Grossman-Clarke et al. 2005), and allows for the fact that most network weather sites have a core inner locale of the station itself (ca. $25 \times 25 \mathrm{~m}$ ) before the surrounding land cover starts a short distance away from the site, as well as generally allowing for the capture of more of the regional development process around weather sites. None of the sites are in complex locales-close to major urban canyons-where results would largely depend on the exact placement of the sensor in that environment.

\subsection{Development zones (DZs)}

Based on the housing completion maps and our general knowledge of land use patterns in the region, we developed a DZ typology of weather stations that included (1) stations in the inner CORE of the urbanized area where little new construction occurred, (2) INFILL locations that were clearly part of the urbanized area in 1990 but became more densely settled by 2004, (3) AGFRINGE locations centered in areas of new construction on former irrigated agricultural lands, (4) DESFRINGE sites where new construction has replaced open desert land, and (5) EXURBAN locations outside the built-up urbanized area (Fig. 1). The EXURBAN sites were mostly near agricultural locations or dams and lakes owing to the ease of access of these sites in a complex terrain considerably distant to the city.

The typology of the weather station sites generally relates to the recommended spatial classification of urban forms arranged according to their ability to impact local climate, as presented by Oke (2006). Our EXURBAN category corresponds to Oke's (2006) Type 7 category of scattered houses in natural land cover area. Our AGFRINGE and DESFRINGE sites are rough equivalents of Type 5 sites (medium, low density suburban), and our CORE and INFILL sites relate to Type 3 sites (highly developed, medium density urban) in Oke's (2006) classification. Our typology differs because it is based on changes in the built environment in addition to the nature of built environment itself. We note that little change occurred in the CORE and EXURBAN sites, and that rapid change occurred in INFILL locations and in the 2 urban fringe sites AGFRINGE and DESFRINGE (Table 1).

\subsection{Regional synoptic variable}

We used a synoptic variable to account for inter-annual variation in temperatures experienced across the weather network. Sheridan's (2002) spatial synoptic classification (SSC2) scheme was employed (available at http://sheridan.geog.kent.edu/ssc.html, expressed as results for the SSC2 classification). For June, $64 \%$ of the days are typed dry tropical with light winds $(<5 \mathrm{~m}$ $\mathrm{s}^{-1}$ ), and another $20 \%$ of days are associated with cool air intrusions related to troughs that have developed in the Western USA that reduce mean monthly minimum temperature. In our analysis, the variable used was the number of days in June that a weather type is characterized by this second category, defined in SSC2 as Dry Moderate (later coded as DRYMOD). We conducted a correlation analysis of the frequency of days in June classified as a particular weather type by SSC2 against June monthly mean minimum temperature. The highest correlation $\left(\mathrm{r}^{2}=0.75\right.$, inverse relationship) was observed between the frequency of the DRYMOD weather type per month and monthly mean minimum temperature. In June, the recurrent Dry Tropical weather type brings warm nights in general, as do some transitional weather types and infrequent moist weather types. Thus, during the study period, the dry tropical frequencies per se only correlated with minimum temperature variation with an $\mathrm{r}^{2}$ of 0.09 .

When using SSC2, we understand that one should exercise caution because the SSC2 and the frequencies determined from it might conceivably contain an 'urban effect' as a consequence of the derivation of weather types that enter the catalog. This could be so because surface data are used in its derivation, often obtained from major first-order weather sites within or near urban areas. This would mean that there could be discontinuities in the frequencies of various categories of daily weather types. This could certainly be the case if the main station used showed a very significant time trend of weather elements attributable to local effects. The Sky Harbor International Airport site (coded PHX in the SSC2-derived data) may represent an example of this influence. However, we consider that this is not the case for Phoenix, and that our use of this factor in this study is warranted on several grounds: (a) a nearby station - Tucson, Arizona - shows similar temporal patterns and variability to Sky Harbor for the June 1990 to 2004 period, and the Tucson airport locale is entirely outside of any Tucson urban effect (Comrie 
2000), (b) independent analysis of time trends in temperature for the Sky Harbor Airport station for the period 1990 to 2004 (and, in addition, our analysis herein) shows no major increase or major trend in temperature (however, prior to 1990 there was a considerable trend in temperature at Sky Harbor Airport; see e.g. Brazel et al. 2000, Baker et al. 2002), and (c) there is no obvious time trend in the Dry Tropical or DRYMOD types revealed in the SSC2 catalog within the period 1990 to 2004. Dry Tropical and DRYMOD days are related to the frequency of ridging and troughing in the Western USA during June, as determined by a separate composite analysis that used the NCEP/NCAR reanalysis data (www.cdc.noaa.gov/Composites/Day/). As an illustration, we chose a mid-study period year (1998) to demonstrate the SSC2 weather type and associated atmospheric conditions (Figs. 3 \& 4). We com-

a. 500mb Geopotential Height (m), June 7-10

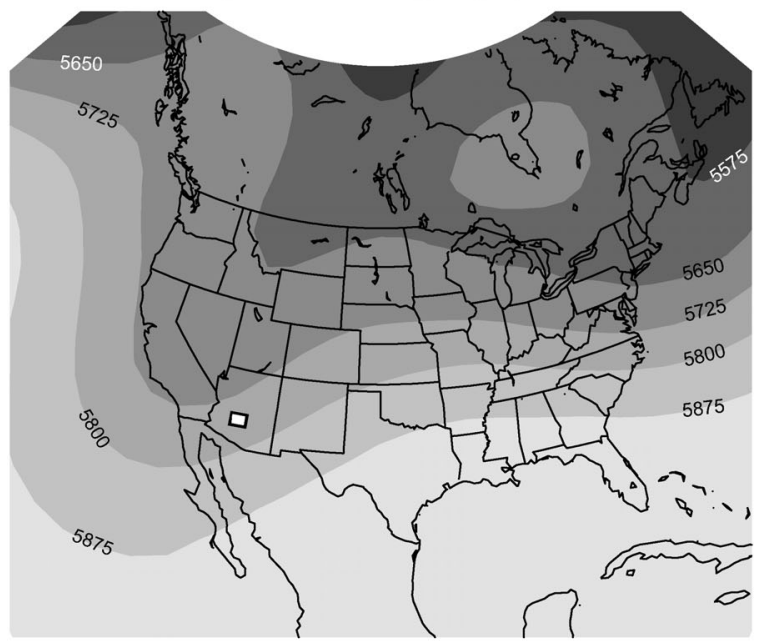

c. $850 \mathrm{mb}$ Air Temperature $\left({ }^{\circ} \mathrm{C}\right)$, June 7-10

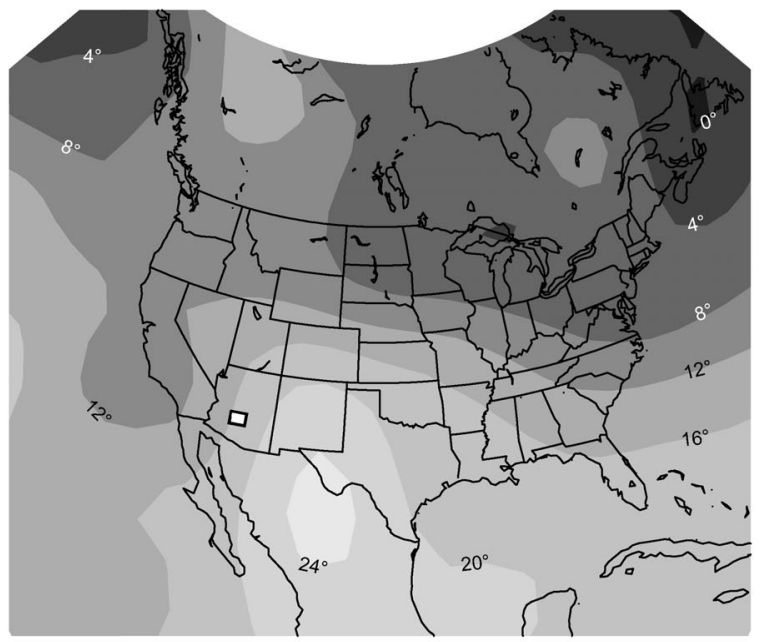

posited a sample run of days catalogued as DRYMOD (June 7 to 10) and Dry Tropical (June 19 to 22) in the SSC2, and displayed the $500 \mathrm{mb}$ geopotential height surface and $850 \mathrm{mb}$ temperature pattern over the USA, and Sky Harbor's hourly air temperature and dew point during these 2 periods. Generally, it holds true that when DRYMOD is prevalent in the catalog, troughing over the Southwestern USA occurs with cooler upper level and surface temperatures. A more thorough analysis of the SSC2 catalog values vs. synoptics and circulation characteristics for this time of year is certainly warranted, but is beyond the scope of this study. Here we simply chose to use the DRYMOD daily weather type code (summed over a monthly time scale) for the period 1990 to 2004 to evaluate the relative role of regional weather effects on the minimum temperature from year to year.

\section{b. $500 \mathrm{mb}$ Geopotential Height (m), June 19-22}

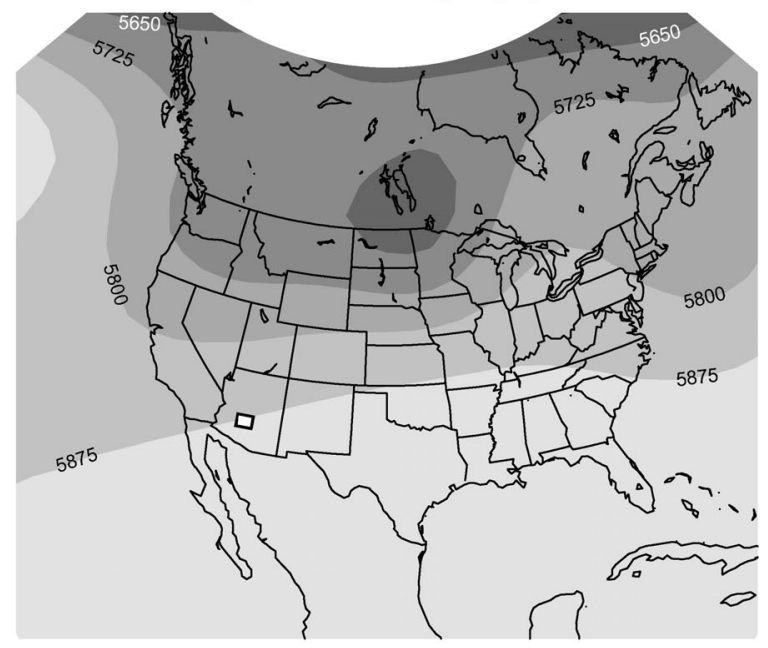

\section{d. $850 \mathrm{mb}$ Air Temperature $\left({ }^{\circ} \mathrm{C}\right)$, June 19-22}

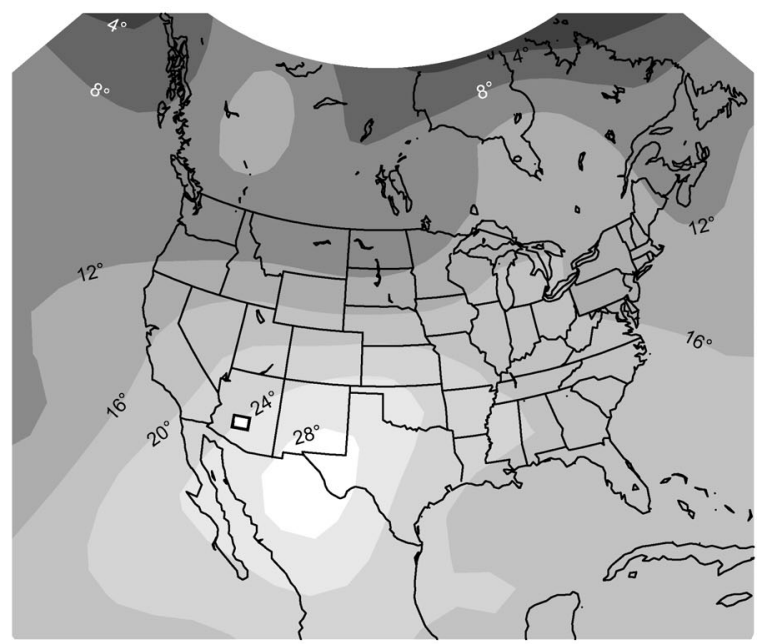

Fig. 3. Examples of $(a, c)$ dry moderate and $(b, d)$ dry tropical weather type conditions over North America for selected periods in June 1998. Data are $500 \mathrm{mb}$ geopotential heights and $850 \mathrm{mb}$ air temperature. Black box: study area 


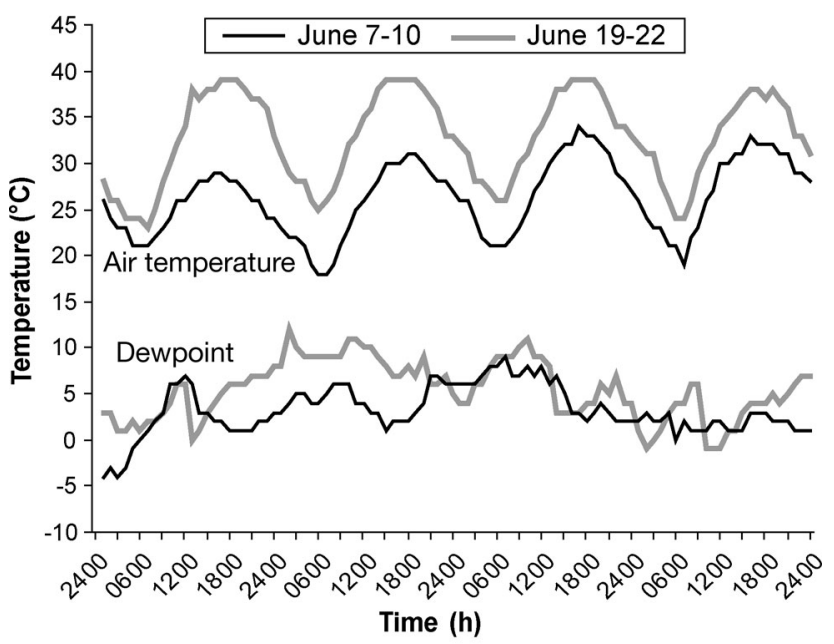

Fig. 4. Hourly air temperature and dew point for periods shown in Fig. 3, Phoenix Sky Harbor International Airport Automated Surface Observing System (first-order weather station)

\subsection{Statistical model}

Our analysis evaluated the effects of the cumulative number of new homes constructed in year $j$ (HOUS$\mathrm{ING}_{j}$ ), the number of days in a June month corresponding to the dry moderate weather conditions in year $j$ $\left(\mathrm{DRYMOD}_{j}\right)$, and DZ (including AGFRINGE, DESFRINGE, CORE, EXURBAN, and INFILL) on mean June minimum temperature in year $j\left(\mathrm{TEMP}_{j}\right)$. In the first stage of the analysis, HOUSING and DRYMOD were classified as covariates, whereas DZ was analyzed as a treatment effect (i.e. as a dummy variable). Fitting the data to the full model allowed us to evaluate interactions between DZ and the 2 confounding variables and test for the equality of slopes for each covariate. Our goal was to determine whether DZ affects the way DRYMOD and HOUSING influence temperature. After using a CONTRAST command in SAS version 9.0, we were able to conclude that there was no reason to consider any interaction terms: the slope coefficients of the 2 confounding variables do not differ significantly across DZs at the 0.05 level of significance (see Table 2).

Based on this conclusion, we proceeded with the reduced-form analysis of covariance (ANCOVA) model expressed below in Eq. 1

$$
\operatorname{TEMP}_{i j}=\mu+\sum_{k=1}^{4} \alpha_{k} x_{k i j}+\sum_{l=1}^{2} \beta_{l} z_{l i j}+e_{i j}
$$

where $i=$ treatment effects, $j=$ number of observations, $x=4$ book-keeping variates for DZs, $\mu=$ intercept, $z=$ 2 continuous variables DRYMOD and HOUSING, $e=$ random error term that is assumed to be normally distributed and $\alpha_{k}$ and $\beta_{l}$ are coefficients.
The reduced-form ANCOVA allowed us to examine whether intercepts vary significantly among the $5 \mathrm{DZs}$. Assuming that there are significant differences, we proceeded to estimate coefficients $\left(\alpha_{k}\right.$ and $\left.\beta_{l}\right)$ that can be used to predict changes in temperature for DRYMOD, HOUSING, AGFRINGE, DESFRINGE, CORE, and INFILL. We excluded EXURBAN from this phase of the analysis because it is known automatically when AGFRINGE, DESFRINGE, CORE, and INFILL are known. The constant in the main model could be interpreted as representing estimated temperature at EXURBAN sites not yet affected by the urbanization process. The $\alpha$ coefficients for AGFRINGE, DESFRINGE, INFILL, and CORE represent the change in temperature relative to EXURBAN sites.

\section{RESULTS}

\subsection{UHI variations from 1990 to 2004}

To investigate broad trends in the areal extent and magnitude of the UHI, we show as an example three 5 yr mean patterns for June monthly mean minimum temperature using ordinary kriging and an exponential statistical model to interpolate the air temperatures in GIS (Fig. 5). The monthly mean minimum temperature distribution is characteristic of a UHI pattern with a magnitude of 2 to $4 \mathrm{~K}$, comparable to Fast et al.'s (2005) general UHI findings for Phoenix. The series shows a heat island in Phoenix that expanded as the population grew from 2.2 million in 1990 to 3.7 million in 2004. The shape of the heat island changed only slightly between the first and second time period, but expanded substantially in the most recent $5 \mathrm{yr}$ period. The intermediate 5 years were dominated by higher than normal DRYMOD days, resulting in unusually cool temperatures in Phoenix. Our results are also comparable with those of Alcoforado \& Andrade (2006), who observed a UHI of ca. $3 \mathrm{~K}$ for Lisbon (population 2.7 million) in their analysis of sky view factor (SVF) and percent built up area vs. nocturnal temperatures. Our results are also comparable with a previous, limited analysis by Brazel et al. (2000) of selected urban CORE sites in relation to a rural desert location southeast of the urban area.

\subsection{Results of statistical analysis}

The slope coefficients of the DRYMOD and HOUSING variables did not vary significantly among the $5 \mathrm{DZs}$ (Table 2). In other words, location within the urban area per se did not affect the process of how the DRYMOD and HOUSING variables impact the variability of TEMP. 
DRYMOD is a broad regional process, and we expected that its impact on all sites would be similar. The impact of HOUSING, through unifying processes of heat retention owing to changing SVF and heat storage changes near weather sites, also appeared to act similarly among all zones.

However, there were significant differences in the intercept coefficients between some of the DZs (Table 3). The AGFRINGE zone differed from the CORE and INFILL sites at $\mathrm{p}<0.05$, and from the DESFRINGE at $\mathrm{p}<0.10$. AGFRINGE was not significantly different from EXURBAN. AGFRINGE and EXURBAN have similar intercepts because EXURBAN sites used for this study were also either near water bodies (dams or lakes) or near the strong influences of agricultural, wellwatered landscapes. The INFILL and CORE sites differed significantly $(p<0.05)$ from every other zone, indicating that both are distinctive in terms of their heat retention factors and likely advective properties.

Coefficients derived from the ANCOVA showed the effects of the independent variables on TEMP, using
Table 2. Full model allowing interactions between categorical and continuous variables, which should be reduced to an ANCOVA model that does not allow interaction terms, because there was no statistically significant result to reject $H_{0}$ of equal slopes for covariates

\begin{tabular}{lccccc} 
Contrast & df $\begin{array}{c}\text { Contrast sum } \\
\text { of square }\end{array}$ & $\begin{array}{c}\text { Mean } \\
\text { square }\end{array}$ & $F$ & $p$ \\
\hline $\begin{array}{l}\text { Test slopes for HOUSING } \\
\text { Test slopes for DRYMOD }\end{array}$ & 4 & 7.735 & 1.934 & 0.81 & 0.5169 \\
& & 6.017 & 1.504 & 0.63 & 0.6393 \\
\hline
\end{tabular}

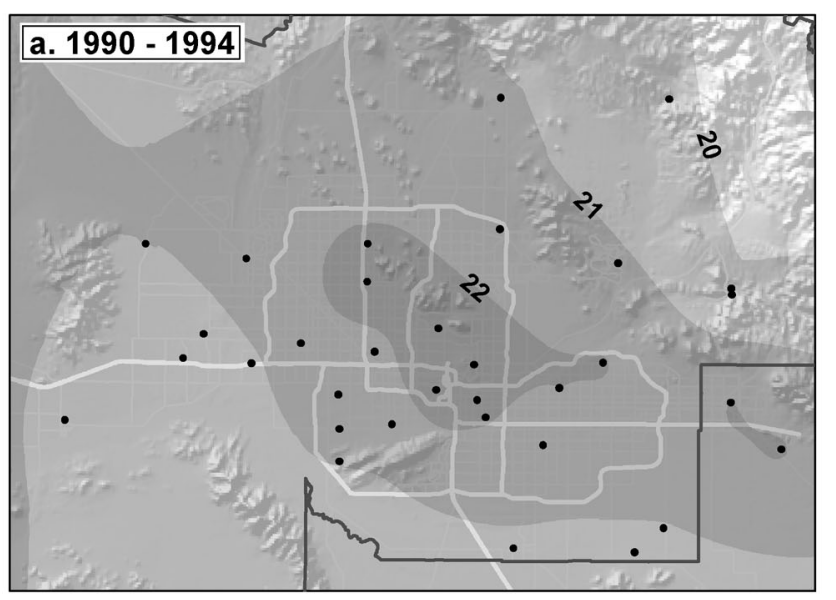

EXURBAN sites as the point of reference. The CORE and INFILL temperatures were $2.2 \mathrm{~K}$ and $1.0 \mathrm{~K}$ higher than EXURBAN sites, respectively, whereas the DESFRINGE was $0.5 \mathrm{~K}$ higher. The coefficient of AGFRINGE was not statistically different from that of EXURBAN. Overall, the results indicate a strong effect of zone type on temperature. Given that housing completion is in the model, it appears that regional location influences the intensity of the UHI above and beyond the local effects of new housing construction. Results support the call by Oke (2006) to report UHI findings by morphology and zones of a city
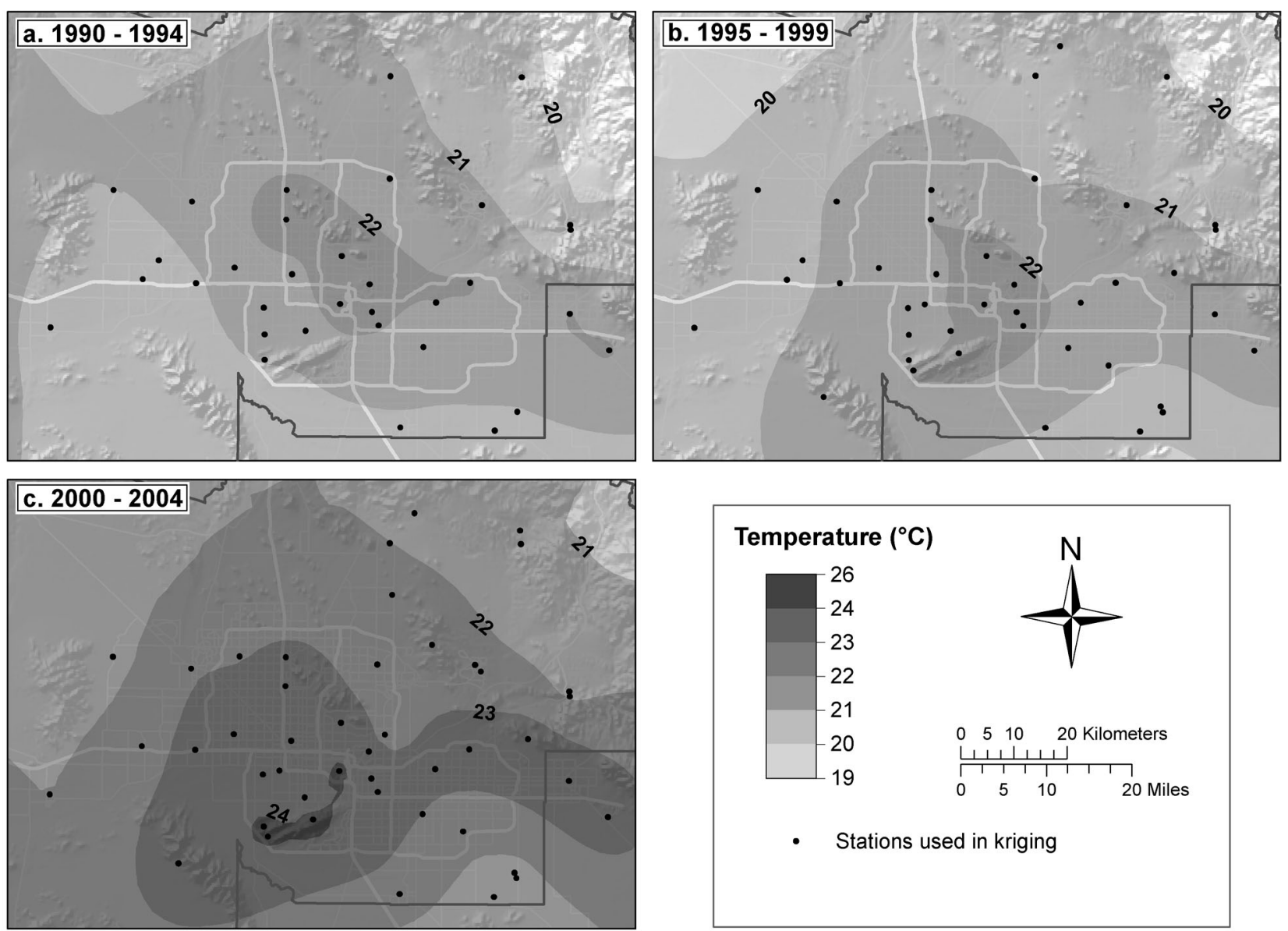

Fig. 5. Monthly mean minimum air temperature patterns (using ordinary kriging methods) from 1990 to 2004 in 5 yr increments 
Table 3. Results of tests of significant differences between intercept coefficients. The ANCOVA model should be tested to determine whether there are urban development zone effects on June minimum temperature. This table demonstrates that not all cases have statistically insignificant results, which allowed us to keep the ANCOVA model. See Table 1 for abbreviations

\begin{tabular}{|lrccrr|}
\hline & AGFRINGE & CORE & DESFRINGE & EXURBAN & INFILL \\
\hline AGFRINGE & & $<0.0001$ & 0.0560 & 0.6651 & $<0.0001$ \\
CORE & $<0.0001$ & & $<0.0001$ & $<0.0001$ & $<0.0001$ \\
DESFRINGE & 0.0560 & $<0.0001$ & & 0.0384 & 0.0283 \\
EXURBAN & 0.6651 & $<0.0001$ & 0.0384 & & $<0.0001$ \\
INFILL & $<0.0001$ & $<0.0001$ & 0.0283 & $<0.0001$ & \\
\hline
\end{tabular}

\section{THE HOUSING EFFECT}

Based on the HOUSING coefficient in Table 4 (noted above), the construction of 1000 new homes in the buffer surrounding a site is estimated to increase temperature by $1.4 \mathrm{~K}$ within various $\mathrm{DZ}$ areas. Inspection of aerial photos of many of the individual weather sites that were surrounded by development from 1990 to 2004 (e.g. Collier, Laveen, Crossroads, Sun Lakes, and Corbell; Fig. 1, Table 1) revealed that it would take between 700 and 1000 homes

in order to facilitate proper intercity comparisons and to unravel the broader influences of urban form on temperatures.

The DRYMOD and HOUSING variables were significantly related to TEMP, holding DZ constant (Table 4 ). The 2 variables acted as expected. High values for the DRYMOD variable resulted in cooler temperatures, whereas high levels of new-home construction caused warming owing to the combination of reductions in SVF and addition of heat-retaining surfaces (roofs, asphalt, cement, etc.) to a given neighborhood. In June, the average number of SSC2 DRYMOD days is $\sim 3$ to 4 per month, which on average would mean a cooling impact of some 1.1 to $1.4 \mathrm{~K}$ on the monthly mean minimum temperature. The HOUSING impact coefficient is $+0.0014 \mathrm{~K}$ per home completion, or $+1.4 \mathrm{~K}$ per 1000 homes (equivalent to complete build up around a weather site in given a buffer size of $1 \mathrm{~km}$ ). There is variability around this value ( $\mathrm{SE}=$ $0.4 \mathrm{~K}$ ), partly because not all new homes are alike, but an inventory of the entire home completion data set revealed mostly repetitive, single-family, similar style residences. A more detailed breakdown of the HOUSING impact coefficient across the rapidly developing zones of the metropolitan area by morphology of house styles would require further analysis with climate research sampling that is not possible with the limited number of fixed sites we analyzed in this study.

Table 4. Results of ANCOVA with average June minimum temperature in year $j$ as dependent variable; $\alpha, \beta$, and $\mu$ are explained in Eq. (1). HOUSING: new homes constructed; DRYMOD: dry moderate weather conditions; AGFRINGE: agricultural fringe; DESFRINGE: desert fringe

\begin{tabular}{|lccrr|}
\hline Parameter & Estimate & SE & $t$ & $\mathrm{p}$ \\
\hline Intercept & $\mu=21.818$ & 0.195 & 112.15 & $<0.0001$ \\
HOUSING & $\beta_{1}=0.0014$ & 0.0004 & 3.07 & 0.0022 \\
DRYMOD & $\beta_{2}=-0.3588$ & 0.0238 & -15.06 & $<0.0001$ \\
AGFRINGE & $\alpha_{1}=0.1016$ & 0.2347 & 0.43 & 0.6651 \\
DESFRINGE & $\alpha_{2}=0.5124$ & 0.2470 & 2.08 & 0.0384 \\
INFILL & $\alpha_{3}=0.9740$ & 0.2250 & 4.33 & $<0.0001$ \\
CORE & $\alpha_{4}=2.2105$ & 0.2215 & 9.98 & $<0.0001$ \\
\hline
\end{tabular}

in the chosen buffer zone to build out a dense neighborhood of typically sized, single-family homes. In order to provide an interpretation of the theoretical heat retention effect through factors such as the SVF (Svensson 2004, Unger 2004), we estimated a simple relation between numbers of homes per unit area around a site and a ground reference level SVF. We made this estimate for the end points of 1990 and 2004 by calculating typical height/width (H/W) ratios among homes, given home density and spacing in the buffer, then by converting to a mean SVF for middistance among the homes using a simple expression relating H/W to SVF (SVF = $0.2905 \ln [\mathrm{H} / \mathrm{W}]+0.4815$, a relationship fitting Oke's [1981] scale model results). We used the results of a field study by Hartz et al. (2006) to aid in determining the relationship between density, spacing, and house height and size in order to estimate the SVF. Hartz et al. (2006) obtained field estimates of SVF for a range of housing densities by mapping the sky horizon among homes and converting these data to SVFs. We consider our approximations for all weather sites to be reasonable, given the approximation we used for SVF. It should be noted that our calculation is primarily based on the spacing among homes and the impact that SVF variability would have on temperature as a consequence of the HOUSING variable alone.

Our results of SVF calculations indicated that the majority of locations would have experienced a reduction in HOUSING SVF of less than 0.20 in the weather site buffer zones over the study time period. Only about $20 \%$ of sites experienced reductions in SVF from 1990 to 2004 that exceeded 0.20. Our estimates of SVF for housing areas (from a mean of 0.99 in 1990 to a mean of 0.83 in 2004) were somewhat consistent with, but slightly higher than, typical SVF values estimated by Unger (2004) and Svensson (2004) for variations within their reported single-family neighborhoods, and were very similar to a single-family residential value (0.85) reported by Grimmond et al. (2001). Most of the residential areas around our weather sites were not fully built up between 1990 and 2004, with the 
exception of some outliers of very densely built neighborhoods surrounding weather sites, where values of mean buffer zone SVF were reduced to $<0.8$, which was closer to measured values typical of Hartz et al.'s (2006) study of a fully-developed, compact, high density desert fringe neighborhood in the Phoenix area.

Regression equations determined by Unger (2004) and Svensson (2004) imply typical magnitudes of residential warming compared with rural counterparts, ranging between $0^{\circ} \mathrm{C}$ for an SVF of 0.99 and 1.5 to 2.5 $\mathrm{K}$ for SVF of 0.83. For an SVF reduction from 0.99 to 0.83 (mean change across all sites), our statistical results would imply a temperature change attributable to HOUSING around a site of only $0.3 \mathrm{~K}$. For a reduction to an SVF much lower than 0.80, the temperature increase would approach 1.0 to $1.5 \mathrm{~K}$, which is lower than residential warming values estimated by other studies. To reconcile this, some points should be noted: (1) our SVF buffer calculations would not necessarily be explicitly representative of the weather station locales, because most stations are not located right between narrow spacings among homes in a neighborhood, but nearby where the SVF would be greater, and (2) the DZ (which accounts for the type of development landscape) accounts for further heating beyond the HOUSING effect. The HOUSING and DZ factors together yield an UHI effect ranging from $3.6 \mathrm{~K}$ in the CORE to $1.9 \mathrm{~K}$ at the DESFRINGE, assuming the build up of 1000 homes. Considering both DZ and HOUSING, our results are very close to those of GrossmanClarke et al. (2005) and Hedquist \& Brazel (2006) of 2 to $3 \mathrm{~K}$ heating in residential areas of Phoenix above rural background levels (employing MM5 modeling for the former, and mobile transect sampling for the latter). In a similar multiple regression approach to heat island evaluation of Stolberg, Germany, Kuttler et al. (1996) found a $0.35 \mathrm{~K}$ or $10 \%$ so-called 'sealed area' rate of temperature increase across the city (streets, city squares, buildings within $200 \mathrm{~m}^{2}$ of measuring points from mobile sampling). This would yield ca. 3 to $4 \mathrm{~K}$ for fully built places and is comparable with our heating rate due to housing change and associated DZ.

\section{CONCLUSIONS AND REMARKS}

The UHI spatial and temporal properties are related to both climatic and human forces operating at a range of spatial scales. In this study, we attempted to integrate climate and urban-growth variables to explain the air temperatures in and around the Phoenix metropolitan area between 1990 and 2004. Results revealed that the spatio-temporal variation in June minimum temperature stems from large-scale synoptic processes that bring cooler temperatures into the region on about
$20 \%$ of June days, and the pace of new housing construction immediately surrounding weather stations within a particular DZ. Owing to the fact that DZ did not significantly affect the slope coefficients for DRYMOD and HOUSING, we concluded that the effects of synoptic condition and new home construction did not vary significantly across the urban region.

Our independent variables account for spatial variation (DZ), temporal variation (DRYMOD), and a combination of the two (HOUSING). The size of the coefficients indicate the estimated effects of moving from one type of urban development to another. For example, the agricultural fringe added just $0.1 \mathrm{~K}$ to exurban sites, which was not statistically significant. The desert fringe added $0.5 \mathrm{~K}$ and infill locations $1.0 \mathrm{~K}$, and the urban core was $2.2 \mathrm{~K}$ warmer than the rural countryside. The additive effects of new home construction (1.4 K per 1000 homes) and DZ produced estimates of the UHI effect that are quite comparable with levels in cities of comparable size.

Model coefficients provide planners and city officials with a tool to estimate the temperature effects of new home construction. In Greater Phoenix, where more than 60000 building permits were issued for residential units in 2004, urban growth has a profound influence on localized temperature conditions. It is commonplace for entire neighborhoods to sprout up in a matter of months and for weather stations to be completely 'surrounded' by urban development. Potential homeowners also can make a more accurate prediction of the long-term climate consequences of new construction, depending on where they are located and the pace of new construction. The overall gained results and coefficients developed in the statistical approach of this study are certainly specific to the Phoenix climate and setting. However, the role of housing on warming is comparable with findings elsewhere.

Acknowledgements. This study is based upon research supported by the National Science Foundation under Grant No. SES-0345945 Decision Center for a Desert City (DCDC). Any opinions, findings and conclusions or recommendation expressed in this study are those of the authors and do not necessarily reflect the views of the National Science Foundation (NSF). We thank the Maricopa Association of Governments for access to housing completion data; Nancy Selover of the Office of Climatology, Arizona State University, for access to PRISMS and NOAA data; Nancy Jones, Theresa Ip, and Michelle Schwartz of DCDC for calculating housing data for buffer zones around weather sites and editing the manuscript; Jon Skindlov, research scientist at the Salt River Project, for reading the manuscript and providing historical aerial photos of some of the PRISMS site locales; Donna Hartz and Barbara Trapido-Lurie, Department of Geography, for providing SVF data for several desert fringe neighborhoods from a field study, and for cartography. 


\section{LITERATURE CITED}

Alcoforado MJ, Andrade H (2006) Nocturnal urban heat island in Lisbon (Portugal): main features and modeling attempts. Theor Appl Climatol 84:151-159

Arnfield AJ (2003) Two decades of urban climate research: a review of turbulence, exchanges of energy and water, and the urban heat island. Int J Climatol 23:1-26

Baker LC, Brazel AJ, Selover N, Martin C, McIntyre N, Steiner FR, Nelson A, Mussacchio L (2002) Urbanization and warming of Phoenix (Arizona, USA): impacts, feedbacks, and mitigation. Urban Ecosyst 6:183-203

Balling RC, Brazel SW (1987) Time and space characteristics of the Phoenix urban heat island. J Ariz-Nev Acad Sci 21:75-81

Brazel AJ, Verville HJ, Lougeay R (1993) Spatial-temporal controls on cooling degree hours: an energy demand parameter. Theor Appl Climatol 47:81-92

Brazel AJ, Selover N, Vose R, Heisler G (2000) Tale of two climates-Baltimore and Phoenix urban LTER sites. Clim Res 15:123-135

Christakos G (2000) Modern spatiotemporal geostatistics. Oxford University Press, New York

Christakos G, Serre ML, Kovitz JL (2001) BME representation of particulate matter distribution in the state of California on the basis of uncertain measurements. J Geophys Res 106:9717-9731

Comrie AC (2000) Mapping a wind-modified urban heat island in Tucson, Arizona (with comments on integrating research and undergraduate learning). Bull Am Meteorol Soc 81:2417-2431

Cooper G (1998) Air-conditioning America: engineers and the controlled environment, 1900-1960. Johns Hopkins University Press, Baltimore, MD

Fast JD, Torcolini JC, Redman R (2005) Pseudo-vertical temperature profiles and the urban heat island measured by a temperature data logger network in Phoenix. J Appl Meteorol 44:3-13

Gammage G Jr (1999) Phoenix in perspective: reflections on developing the desert. Herberger Center for Design, Tempe, AZ

Gober PA (2006) Metropolitan Phoenix place making and community building in the Desert. University of Pennsylvania Press, Philadelphia, PA

Gober PA, Burns EK (2002) The size and shape of Phoenix's urban fringe. J Plan Educ Res 21:379-390

Editorial responsibility: Helmut Mayer,

Freiburg, Germany
Grimmond CSB (2006) Progress in measuring and observing the urban atmosphere. Theor Appl Climatol 84:3-22

Grimmond CSB, Potter SK, Zutter HN, Souch C (2001) Rapid methods to estimate sky-view factors applied to urban areas. Int J Climatol 21:903-913

Grossman-Clarke S, Zehnder JA, Stefanov WL, Liu Y, Zoldak MA (2005) Urban modifications in a mesoscale meteorological model and the effects on near-surface variables in an arid metropolitan region. J Appl Meteorol 44: $1281-1297$

Hartz DA, Prashad L, Hedquist BC, Golden J, Brazel AJ (2006) Linking satellite images and hand-held infrared thermography to observed neighborhood climate conditions. Remote Sens Environ 104:190-200

Hawkins TW, Brazel AJ, Stefanov WL, Bigler W, Saffell EM (2004) The role of rural variability in urban heat island determination for Phoenix, Arizona. J Appl Meteorol 43: 476-486

Hedquist BC, Brazel AJ (2006) Urban, residential, and rural climate comparisons from mobile transects and fixed stations: Phoenix, Arizona. J Ariz-Nev Acad Sci 38:77-87

Kuttler W, Barlag AB, Rossmann F (1996) Study of the thermal structure of a town in a narrow valley. Atmos Environ 30:365-378

Oke TR (1981) Canyon geometry and the nocturnal heat island: comparison of scale model and field observations. J Climatol 1:237-254

Oke TR (2006) Towards better scientific communication in urban climate. Theor Appl Climatol 84:179-190

Pon B, Stamper-Kurn DM, Smith CK, Akbari H (1998) Existing climate data sources and their use in heat island research. Available at: http://eetd.lbl.gov/EA/Reports/41973/

Sheridan SC (2002) The redevelopment of a weather-type classification scheme for North America. Int J Climatol 22:51-68

Souch C, Grimmond S (2006) Applied climatology: urban climate. Prog Phys Geogr 30:270-279

Stabler LB, Martin CA, Brazel AJ (2005) Microclimates in a desert city were related to land use and vegetation index. Urban Forest Urban Green 3:137-147

Svensson MK (2004) Sky view factor analysis-implications for urban air temperature differences. Meteorol Appl 11: 201-211

Unger J (2004) Intra-urban relationship between surface geometry and urban heat island: review and new approach. Clim Res 27:253-264

Submitted: July 11, 2006; Accepted: October 19, 2006

Proofs received from author(s): January 10, 2007 